\title{
Crisis institucional y justicia distributiva a la luz del liberalismo de John Rawls: Aportes para el Trabajo Social
}

\author{
Institutional crisis and distributive justice in the light of John \\ Rawls' liberalism: Contributions for Social Work \\ Crise institucional e justiça distributiva à luz do liberalismo de \\ John Rawls: contribuições para o Serviço Social
}

Catalina Ruz Escobar*

\begin{abstract}
RESUMEN
El artículo examina elementos para analizar la crisis institucional en la coyuntura política y social a la luz de los planteamientos de John Rawls. Se trata de exponer un marco teórico y normativo en torno a la justicia desde su enfoque institucional, la equidad y la distribución. Con esto se presentan aportes para el Trabajo Social, a partir del vínculo del quehacer profesional y al interior del entramado institucional que incide en el alcance de la justicia social.
\end{abstract}

\section{SUMMARY}

This article examines elements that analyze the institutional crisis in a political and social context in the light of John Rawls' ideas. The aim is to present a theoretical and normative framework on justice from its institutional approach, equity, and distribution. We offer a contribution to Social Work from the link of professional work and within the institutional framework that affects the scope of social justice.

\section{RESUMO}

$\mathrm{O}$ artigo examina elementos para analisar a crise institucional no contexto político e social à luz das propostas de John Rawls. Trata-se
Palabras clave: crisis institucional, liberalismo de Rawls, teoría normativa, justicia distributiva, Trabajo Social.

Key words: institutional crisis, Rawls' liberalism, normative theory, distributive justice, Social Work.

Palavras-chave: crise institucional,

* Doctora por la Universidad de Barcelona en Ciudadanía y derechos humanos. Docente de la Escuela de Trabajo Social de la UCSH. Parte del Núcleo de Justicia social y derechos humanos. Licenciada en Trabajo Social UCSH. cruz@ucsh.cl 
de expor um marco teórico e normativo em torno da justiça desde seu ponto de vista institucional, a equidade e a distribuição. Com isto, são apresentadas contribuições para o Serviço Social, a partir do vínculo da atividade profissional e no interior da estrutura institucional que incide no alcance da justiça social. liberalismo de

Rawls, teoria normativa, justiça distributiva, Serviço Social. 


\section{Introducción}

La crisis, en un sentido básico, acusa un cambio, una inoperancia del sistema. En este sentido, entendemos la crisis desde la noción de "coyuntura", pues esta muestra las explicaciones a considerar en la crisis en las instituciones públicas (políticas y económicas de la sociedad).

Para analizar la crisis institucional, si bien nos dotaremos de la batería de John Rawls en el plano normativo, también es preciso aproximarnos a un plano más práctico que, ligado al término "crisis", trae consigo la necesidad de transformación y de atender a la coyuntura que configura una situación concreta de inestabilidad, de riesgo y de peligro.

Dicho esto, es preciso presentar un marco introductorio que exponga una concepción sobre la coyuntura en tres cuadros que constituyen la crisis. Esto se hará antes de entrar a los argumentos de Rawls sobre la justicia distributiva, cuyo ideal normativo muestra un parámetro para evaluar el mal funcionamiento de las instituciones.

En este sentido, la coyuntura remite a un momento determinado en el cual se expresan los aspectos dominantes de una situación concreta encuadrada por la intersección de una complejidad (Bermudo, 1975). A efectos de este texto, distinguiremos tres cuadros: el político, el económico y el ideológico, en virtud de explicar la coyuntura de la crisis institucional a partir del contexto de estallido social y pandemia por covid-19, que ciertamente han gatillado un incremento de la crisis de las instituciones. El cuadro político que configura la crisis acusa la inoperancia y la ineficacia de las políticas públicas para frenar el descontento, la miseria y el sufrimiento humano, así como también expresa la crisis de la democracia en términos de posibilidades para incidir en las decisiones por parte de la mayoría de la población, cuando estas quedan en manos de los grupos de poder político, que acrecientan la desigualdad y no mejoran la democracia. El cuadro económico contempla, de manera empírico-descriptiva, la precarización de la vida y la falta de recursos materiales para responder a las demandas ciudadanas, al tiempo que incluye las "ayudas" por parte del gobierno a las familias y personas afectadas por la crisis sanitaria. El cuadro ideológico, admite el cuestionamiento y la defensa del modelo neoliberal, por un lado en favor de las clases dominantes o la elite política y empresarial; 
por otro, las demandas de las masas sociales o la multitud ponen de relieve los abusos del neoliberalismo.

Estos tres cuadros explican la coyuntura de lo que llamaremos un "cuadro histórico" (Bermudo, 1975, p. 17), al cual es posible sumar más elementos explicativos de los antecedentes particulares que se constatan en los elaborados diagnósticos sobre el estallido social (en los que aquí no entraremos ${ }^{1}$ ), que evidencian el malestar social y el masivo cuestionamiento al sistema institucional que ordena y regula la sociedad.

En este marco, hay diversas razones para considerar que la crisis institucional viene sucediendo con especial magnitud desde el estallido social del 18 de octubre del 2019 en Chile, mostrando los efectos de la democracia neoliberal en la deslegitimidad de las instituciones de la sociedad chilena cuando éstas se han desvinculado de la justicia, la vulnerabilidad, el sufrimiento, el daño y las víctimas de la crisis actual. En este sentido, el cuadro histórico coyuntural pone en evidencia que las políticas públicas no están diseñadas para cubrir las desigualdades, puesto que los recursos económicos no se usan para garantizar la dignidad en la distribución de bienes y servicios.

El duro confinamiento para evitar la propagación de la covid-19 fue abordado por parte del gobierno con subsidiarias asignaciones a la población que se ubica dentro del $60 \%$ más vulnerable del país, ejemplo de ello es el Bono Covid y el ingreso familiar de emergencia, medidas que no solo fueron insuficientes, sino que han dejado ver la situación de inestabilidad y precarización a la que asistimos, sin resguardo y garantías de protección por parte de la institucionalidad. Así pues, el confinamiento aceleró la vulnerabilidad de los trabajos informales y los llamados emprendimientos. En los sectores más afectados, se activaron prácticas de apoyo mutuo, sobre todo en torno al soporte alimentario con iniciativas como las ollas comunes, organizadas por las propias comunidades en una situación de emergencia y deprivación. En este contexto, la coyuntura en su situación concreta nos conecta con ámbitos de los que se ocupa la justicia social (Agra, 2016) y, en particular, la noción distributiva de ésta.

1 Véase Garcés, M. (2020). 
En este sentido, hay que tener en cuenta que, si bien la coyuntura obedece a un plano práctico, la teoría de Rawls a examinar se ubica en un plano teórico y normativo, que se ocupa de un tipo de diseño orientado en el deber ser: en este caso, de las instituciones sociales para una sociedad justa. Por consiguiente, la dualidad entre teoría y práctica muestra qué tan lejos están las instituciones sociales de la teoría normativa.

Analizar la crisis institucional y comprender el funcionamiento de la justicia distributiva es una tarea necesaria para la intervención del Trabajo Social, que implica no perder de vista las posibilidades prácticas y las condiciones normativas que rigen las instituciones a la hora de aplicar los principios de justicia. Más aún cuando la crisis social muestra que las instituciones no están a la altura de responder a la vida (Rolnik, 2019), a la emancipación y a la transformación social.

Luego de esta introducción a la crisis institucional examinaremos los elementos del enfoque de Rawls. Comenzaremos con aspectos básicos del liberalismo como corriente de pensamiento político ${ }^{2}$. Seguidamente, daremos cuenta de la teoría de Rawls a través de la importancia que el autor da a concepciones tales como el diseño de las instituciones y la concepción del individuo liberal. Para entrar en los aspectos más centrales en relación con la justicia rawlsiana, abordaremos la estructura básica, la justicia distributiva y la justicia como equidad. Finalmente, expondremos algunas críticas a la justicia distributiva de Rawls, que nos sitúan en el debate para repensar algunos aportes al Trabajo Social.

\section{Aspectos básicos del liberalismo}

El liberalismo es una corriente de pensamiento político que nace en el siglo XVII, en Inglaterra. En contra del poder monárquico, defiende la libertad individual y la libertad de pensamiento y de culto. La libertad individual que perseguían los primeros liberales, entre ellos John

2 Cabe decir que el liberalismo contemporáneo tiene distintos exponentes, entre éstos se distingue Robert Nozick, con Anarquía, Estado y Utopía (1974), una robusta teoría liberal que reduce al mínimo el rol del Estado. También cabría destacar a Amartya Sen, con su teoría sobre las capacidades (2009), que se sitúa con relevancia en el debate del liberalismo anglosajón. 
Locke $^{3}$, quien promovía que el individuo era dueño de sí mismo, tendió rápidamente a extrapolarse a la idea de la propiedad privada. Si Descartes dijo pienso, luego existo, podemos imaginar que Locke añade:

"Pienso, luego poseo": soy mi dueño, por lo tanto, soy dueño de todo lo que produzco. Más aún la noción de nuestra propiedad elemental somos nosotros mismos, es decir, nuestras personas y nuestros cuerpos, implica que la propiedad, necesariamente, lleva consigo la libertad. Porque decir que "somos dueños de nosotros mismos" es equivalente a decir que tenemos la libertad de disponer de nosotros mismos, que es el significado de nuestra libertad. (Lassalle, 2010, p. 360)

Lo anterior se relaciona con una idea fundacional del liberalismo (Lassalle, 2010), que fue posicionándose como uno de los presupuestos centrales de su ideología, esto es, la propiedad privada. Así pues, la primacía de la libertad en torno al individuo propietario, concepción basada en un individualismo posesivo (Macpherson, 2005), se expandió por Europa, Norteamérica y se ha ido difundiendo por el mundo como fundamento del valor de la libertad en la cultura capitalista moderna hasta nuestros días. En este sentido, la libertad individual es el valor principal del liberalismo.

Después de varios siglos sin que la filosofía política agitara las discusiones en torno a valores políticos, la obra de John Rawls genera un resurgimiento del debate en el liberalismo respecto de conceptos políticos y modelos para pensar la sociedad justa. En este contexto, se pone de relieve la estructura de un sistema institucional que no solo garantice la libertad, sino también la igualdad, a pesar de apelar a la neutralidad del Estado. Dicho en otras palabras, matiza la idea de la no interferencia del Estado en la concepción de lo que es bueno, puesto que para garantizar la sociedad justa es preciso una concepción de lo que es correcto, la cual entronca directamente con la virtud de la justicia.

3 Locke fundó uno de los partidos que lucharon contra el poder del absolutismo que imponía la monarquía en Inglaterra. A través de su obra Dos tratados sobre el gobierno civil, puso en marcha una reflexión virtuosa de la libertad y de la propiedad privada que, a partir de la conciencia, combatió la corrupción de la persona y del gobierno (Lasalle, 2010). 
En este contexto, el liberalismo y el debate contemporáneo considera que la justicia es el valor primordial para organizar la vida política. Así lo establece Rawls cuando pone en el centro de la estructura de las instituciones políticas a la justicia, con el fin de dar estabilidad al funcionamiento del orden social, por lo tanto, la justicia cumple un rol regulativo vinculado con la concepción clásica de la justicia de Platón, que entraña la aceptación de un orden social, sin conflictos y que vela por un orden estable como modelo de sociedad (Agra, 2016).

Esta idea de no conflictos es resuelta en el liberalismo con la primacía de la libertad de culto, que Rawls en El liberalismo político (1993) justifica a través del pluralismo liberal, un principio que aspira a que convivan diversas concepciones de vida buena. La importancia que Rawls da al pluralismo es esencial al liberalismo, cuyo "origen histórico es la Reforma y sus consecuencias, con las largas controversias acerca de la tolerancia religiosa en los siglos XVI y XVII. Algo parecido a la comprensión moderna de la libertad de culto y de pensamiento empezó entonces" (Rawls, 1993, p. 20). Por ello, el problema central que trata el liberalismo político es "elaborar una concepción de la justicia política para un régimen constitucional democrático que pueda ser aceptada por la pluralidad de doctrinas razonables (pluralidad que será siempre un rasgo característico de un régimen democrático libre)" (p. 14).

Lo anterior sitúa la libertad del individuo como prioridad del liberalismo, por lo tanto, la libertad de crear y elegir una doctrina o concepción de vida buena entraña la capacidad racional de cada persona para hacerlo. Esto último hace posible que, aunque las distintas concepciones de vida buena sean irreconciliables entre sí, es decir, aunque sea imposible conciliar la concepción de una persona que defiende la vida por ejemplo de todas las especies, con otra que solo defiende la vida humana como prioridad en su escala de valores, el liberalismo dirá que no es posible considerar que una vida vale más que la otra, por lo cual, ambas deben ser respetadas, pues todas son válidas en la medida en que respeten que las otras también lo son.

\section{Diseño de instituciones y la concepción del individuo liberal}

La pertinencia de los postulados de la teoría rawlsiana se inscribe en un tipo de diseño institucional que corresponde al ala más progresista 
del liberalismo de la mano de Rawls. Esto es por la versión igualitarista en la que se ubica al autor, al incluir un principio que refiere a la igualdad y a la asignación de bienes primarios que designan un carácter más activo a las instituciones en la prestación igualitaria de ciertos bienes para realizar los planes de vida buena. Con lo cual, desde el ámbito normativo, las instituciones tienen la obligación de velar por la justicia, independiente de las doctrinas comprehensivas o concepciones de vida buena que tengan los individuos.

En este sentido, la justicia es el centro de las instituciones, en tanto una sociedad justa depende de las instituciones justas (Rawls, 1979, 1993). Esta premisa de entrada pone de relieve el funcionamiento institucional, por tanto, parece interesante conocer cuáles son las concepciones normativas predominantes que sirven para evaluar las instituciones según un diseño preestablecido. Siguiendo a Rawls, nos encontraremos con que la responsabilidad de enfrentar las injusticias es de las instituciones, porque estas incumplen los principios que alteran la estabilidad cuando no permiten que las personas desarrollen su autonomía y se autorrealicen, pero, para ello, las instituciones justas requieren contar con ciudadanos que cooperen con el funcionamiento de éstas y acepten que los principios de justicia son los más aptos para llevar cabo sus planes de vida buena.

Cabe señalar que la concepción de "individuo" en el liberalismo de Rawls es moral, esto quiere decir que antepone a su concepción de vida buena lo considerado por las instituciones como justo o correcto. La concepción moral establece que los individuos deben aceptar los principios para una sociedad justa. De este modo, son morales porque consideran lo justo antes de lo bueno.

A su vez, esta concepción plantea que las ideas del bien requieren que todo el mundo sea racionalmente capaz de crear su propia forma de vida buena acorde con los principios de justicia. Por ejemplo, si un individuo decide o elige ser vegetariano, y luego elige ser vegano, es libre y capaz de realizar esta opción como parte de su concepción de vida buena, o si elige transformar ciertos aspectos de su identidad de género porque lo considera bueno para sí mismo, en cuanto a la autonomía y la libertad que realiza, debe poder hacerlo y las instituciones públicas, políticas y sociales no deben impedirlo. En cualquier caso, el individuo tiene la libertad de hacerlo siempre que su concepción de 
vida buena no atente contra los principios de justicia, es decir, que no se imponga sobre los demás como la única forma de vida buena.

La elección de la propia concepción de lo bueno debe ser consecuente con los principios de justicia, o sea, no puede impedir que otras personas desarrollen su libertad de elegir. Esto obedece al respeto frente a las otras formas de vida buena y a la tolerancia que está en el centro del pluralismo liberal. En este sentido, Rawls plantea un acuerdo razonable basado en el respeto de las diferentes formas de vida buena que conviven en una sociedad justa, en la cual los individuos deben estar de acuerdo con principios morales (Rawls, 1979, p. 103). Esto puede parecer una suerte de abstracción de las preocupaciones y conflictos que se dan en la vida real para realizar efectivamente las concepciones de vida buena, más aún si no se cuenta con garantías para llevar a cabo las elecciones vitales que requieren de cierta legalidad para poder ser legitimadas, por lo tanto, las elecciones personales, en tanto confieren un proyecto vital, no pueden ser solo individuales, como Rawls plantea, ni desvinculadas de un contexto amplio, dinámico y político que las comprende (Ruz, 2017). Esto genera inquietudes respecto de la restringida y poco real libertad liberal, al quedar relegada a la elección del individuo, así como pone en evidencia que la teoría liberal de Rawls es individualista ${ }^{4}$, porque admite planes de vida que se cubren de forma individual, que no son parte de una comunidad a la hora de reivindicar sus proyectos de vida. Por ejemplo, siguiendo el mismo caso de opciones alimentarias, alguien que no consume gluten, por los efectos que produce en el ecosistema, por ser monocultivo y por las nuevas alergias que provoca en los organismos humanos, se vería dificultada de alimentarse con la caja de alimentos ${ }^{5}$ otorgada por el gobierno como una prestación universal en la crisis, que en definitiva opera para cumplir con el enfoque igualitarista que propone Rawls, ciertamente insuficiente en su igualitarismo, pero también en el respeto a la libertad

4 Estas ideas son desarrolladas en la investigación doctoral de la autora del presente texto, la cual llevó por título: Las virtudes políticas en el liberalismo contemporáneo: de lo instrumental a lo dialéctico. Defendida el 06 de septiembre del 2017 en la Universidad de Barcelona, Facultad de Filosofía, Programa de doctorado en Ciudadanía y Derecho Humanos. España.

5 La caja de alimentos de la campaña que implementó el gobierno de Piñera en 2020, en la pandemia de covid-19, contenía alimentos no perecibles, entre estos fideos, leche en polvo, tarros de jurel. 
individual, entendida como elecciones de vida buena, cuando queda restringida si no se dispone de medios materiales.

Ahora bien, la justicia liberal se traduce en un diseño de instituciones de la sociedad que satisfacen los principios de justicia, estos son aceptados y adoptados "hipotéticamente" por los individuos, es decir, cuentan con la firma de los individuos como si de un contrato se tratara, para el propósito de regular el orden social. Esto último es lo que plantea el contractualismo como una perspectiva a la cual Rawls adhiere para sostener su teoría hipotética y a-histórica ${ }^{6}$.

\section{La justicia de la estructura básica}

Como ya mencionamos, en Rawls, la justicia es la primera virtud de las instituciones, lo cual denota su enfoque institucionalista centrado en que una sociedad justa depende de instituciones justas. Dicho esto, la estructura básica de la sociedad "es el modo en que las principales instituciones políticas y sociales de la sociedad encajan en un sistema de cooperación social, y el modo en que asignan derechos y deberes básicos que regulan la división de las ventajas que surgen de la cooperación social a lo largo del tiempo" (Rawls, 2002, p. 33).

La justicia, como desarrollará luego, no es la justicia legal, ni una virtud entre otras, sino la virtud básica y fundamental de las instituciones sociales, en consecuencia, la justicia deviene criterio para evaluar las prácticas mismas, un criterio que integra a todos los demás valores y principios. Justicia es la virtud básica y fundamental de las instituciones sociales y, como es sabido, su concepción de la justicia la denomina "justicia como equidad”. (Agra, 2016, p. 79)

El papel de las instituciones para una sociedad justa es central en la teoría de Rawls, en efecto, este es uno de los aspectos que la hacen interesante como una teoría liberal que, al parecer, da un rol importante al sistema público, en tanto le da un papel más activo en

$6 \quad$ El que sea a-histórica restringe la valoración de los procesos sociales históricos y contingentes. Este aspecto es asimilado por la teoría para regular la estructura básica que se abstrae "de las diversas contingencias que acaecen en su seno con objeto de hallar una concepción de la justicia adecuada para regular aquella estructura" (Rawls, 1993, p. 311). 
la medida en que la estructura debe considerar un tipo de diseño institucional que opere como "el marco social de trasfondo en cuyo seno tienen lugar las actividades de las asociaciones y los individuos" (Rawls, 2002, p. 33).

La estructura básica es el principal objeto de la justicia política (Rawls, 2000, p. 33). Su principal función es velar por el cumplimiento de los principios de justicia, que el autor formula de este modo:

Los dos principios capitales rezan como sigue: a) cada persona tiene un derecho igual al más amplio esquema de libertades para todos. b) Las desigualdades sociales y económicas son permisibles siempre y cuando i) sean para el mayor beneficio esperado de los menos aventajados; y ii) anden vinculadas a posiciones y cargos abiertos a todos en condiciones de igualdad equitativa de oportunidades. (1993, p. 307)

Estos principios son el fundamento de una sociedad justa y las instituciones públicas, económicas y sociales deben cumplirlos, de otro modo las personas deben alentar y exigir a las instituciones que los cumplan cuando vean que esto no ocurre. Esta sería una de las formas mínimas de participación por parte de los individuos en la cooperación social. Se trata de individuos con un sentido de justicia intrínseco, cuyo interés por la justicia es interesado y radica en que el cumplimiento de los principios les permite, independiente de la forma en que conciben el mundo, realizar su proyecto de vida.

Si las instituciones no cumplen con los principios, afectan las oportunidades de los individuos y generan injusticias. Estas últimas son vistas como hechos arbitrarios en la vida de las personas y las instituciones deben encargarse de resolverlas. En este sentido, para Rawls, "las arbitrariedades morales no son justas o injustas en sí mismas: no tendría sentido 'reprocharle' a la naturaleza el que nos haya favorecido o desfavorecido en nuestras asignaciones iniciales" (Gargarella, 1999, p. 41). Para nuestro autor, lo que tiene sentido respecto de su compromiso con la igualdad exige "hacer una evaluación sobre la justicia o injusticia de las instituciones básicas de nuestra sociedad" (Gargarella, 1999, p. 41). Ello significa que "la naturaleza no es justa o injusta con nosotros, lo que es justo o injusto es el modo en que el sistema institucional procesa estos hechos de la naturaleza" 
(Gargarella, 1999, p. 41). Dicho esto, la importancia de la estructura básica para una sociedad justa y democrática se encarna en las instituciones políticas y, por tanto, una sociedad es justa en la medida que las instituciones son justas.

Ergo, ¿qué quiere decir que las instituciones sean justas? Básicamente que deben cumplir con los dos principios de justicia que expusimos, y que se pueden acotar en la libertad y la igual libertad. Desde el punto de vista de la estructura básica, los agentes y funcionarios de las instituciones deben trabajar para el respeto de los principios, y los ciudadanos deben cooperar y contribuir con las instituciones vigilando en caso de que éstas no los cumplan.

En este sentido, la justicia social de Rawls es institucionalista, pues plantea que las instituciones públicas tienen la tarea de velar por que ninguna persona sea impedida de gozar de la libertad a la hora de elegir su forma de vida buena. Para ello, los individuos deben aceptar los principios y controlar que las instituciones hagan bien su trabajo. Según Rawls, es necesario que los ciudadanos posean virtudes políticas para que estén dispuestos a denunciar el incumplimiento de los principios de justicia. Esta es la cooperación social que evita los conflictos y contribuye a que las instituciones hagan bien su trabajo.

\section{La justicia distributiva y la justicia como equidad}

La justicia distributiva manifiesta el aspecto procedimental de la teoría de Rawls, cuyo atributo básico es realizar reajustes y distribuir ventajas para la estabilidad de una sociedad bien ordenada. "En concreto, con Rawls la justicia es social y distributiva, afrontando el carácter estructural básico que condiciona el reparto de cargas y beneficios, derechos y deberes, no la justicia en el plano personal" (Agra, 2016, p. 83).

La justa distribución requiere previamente de ciertos valores que los ciudadanos aceptan como asociados a una repartición equitativa. Abarca la totalidad de explicaciones que configuran el discurso político público que aborda los problemas de justicia e igualdad.

Como hemos abordado en los bienes primarios y la cooperación social, la justicia materializada en dichos términos acusa una expresión monopolizada que realiza el dominio político sobre individuos que reciben bienes para llevar a cabo fines individuales. 
Los bienes primarios que Rawls postula son el aspecto distributivo a través del cual los individuos aceptan los términos equitativos y cooperan con el orden para recibir ciertos beneficios. Esto expresa el enfoque procedimental de los bienes distribuidos. Por tanto, la primacía de la justicia influye en el interés de los individuos por el funcionamiento de las instituciones de una sociedad ordenada, en tanto aceptan las cargas de la cooperación social, y admite que todos requieren los mismos bienes para realizar su propia concepción de vida buena, siempre que acepten, exijan y respeten los principios de justicia.

Esto quiere decir que se trata de una sociedad en la que: 1) cada cual acepta y sabe que los otros aceptan los mismos principios de justicia, y 2) las instituciones sociales básicas satisfacen generalmente estos principios y se sabe que generalmente lo hacen (Rawls, 1979, p. 21).

Lo anterior da cuenta de la homogeneidad de los mismos bienes que ofrece, y que acusan un posible problema para la libertad de los individuos respecto de la elección de sus concepciones de vida buena, sobre todo si estos bienes no atienden a estas últimas. Así pues, la justicia concebida en términos distributivos quiere decir que los asuntos públicos de justicia se resuelven por medio de ajustes y repartos de bienes y derechos para que los ciudadanos realicen sus planes individuales. No obstante, pese a que Rawls considera bienes primarios iguales para todos, hay que tener en cuenta, que su liberalismo no pretende modificar la estructura capitalista.

Cabe aproximarnos a la noción de "justicia como equidad”, emparentada con la noción distributiva que plantea Rawls. En una de las primeras conferencias de su obra El Liberalismo político (1993), Rawls parte preguntándose por la necesidad de esclarecer la justicia política. Para ello plantea:

¿Cuál es la concepción más adecuada de justicia para establecer los términos equitativos de la cooperación social entre ciudadanos considerados libres e iguales, y considerados como miembros plenamente cooperativos de la sociedad durante su vida, desde una generación hasta la siguiente? (Rawls, 1993, p. 33)

La respuesta postula que la justicia como equidad entraña la concepción más adecuada. Antes de explicar a qué se refiere esta concepción, podemos considerar que en la pregunta misma hay elementos 
que dan cuenta del enfoque que hemos ido delineando. Así pues, distinguimos el concepto de los "términos equitativos de la cooperación social", que tiene que ver con la distribución, que es la "concepción más adecuada". Aquí, Rawls nos invita a participar de la construcción de una sociedad justa, cuyos términos equitativos de la cooperación social requieren de la aceptación de las cargas y repartos, de las reglas y normas que regulan las conductas de los individuos. En palabras de Rawls:

La cooperación social es cosa distinta de la mera actividad socialmente coordinada; por ejemplo, de la actividad coordinada a base de órdenes dictadas por una autoridad central absoluta. Antes bien, la cooperación social está guiada por reglas y procedimientos públicamente reconocidos que los cooperantes aceptan como apropiados para regular su conducta. (Rawls, 2000, p. 29)

Como hemos visto, esto ocurre en un ámbito hipotético, en el cual los individuos aceptan los términos porque los demás también los aceptan, y porque estos saben que podrán beneficiarse mutuamente, a lo que Rawls llama ventaja racional, "aquello que persiguen los que participan en la cooperación para promover su propio bien" (Rawls, 2000, p. 29).

No olvidemos que el enfoque de Rawls es individualista, por lo tanto, en la cooperación se puede vislumbrar la incidencia de este principio emparentado con el egoísmo, como un criterio de la cooperación social. Aunque Rawls señala que nadie violará los términos de cooperación, porque sabe que hay aceptación mutua, por lo que sería irrazonable no aceptar los términos equitativos de la cooperación, o violarlos solo por beneficio propio, este aspecto parece dar cuenta de que el liberalismo de Rawls admite cierta reciprocidad más que solo individualismo.

Por otra parte, los términos equitativos están vinculados con la justicia distributiva y con la equidad. De hecho, en su última obra $-L a$ justicia como equidad: una reformulación- señala que su teoría debe "orientarnos, digamos, en el espacio (conceptual) de todos los fines posibles, individuales y asociativos, políticos y sociales” (Rawls, 2000, p. 25).

Hay que señalar que lo equitativo tiene que ver con la dimensión igualitarista de la justicia de Rawls, de hecho, es uno de los aspectos 
que más caracterizan a su teoría en el ámbito del liberalismo, pues éste ha defendido en su historia de pensamiento el valor de la libertad por sobre la igualdad. Pese a esto, Rawls busca igualar a las personas a través del reparto de ciertos bienes, que define como bienes primarios, y que son fundamentales para que los individuos de una sociedad justa realicen sus concepciones de vida buena.

La igualdad que remite al segundo principio de justicia se traduce en la idea de los bienes primarios, que "son cosas que los ciudadanos necesitan en tanto que personas libres e iguales, y la exigencia de esos bienes cuenta como una exigencia adecuada" (Rawls, 1993, p. 214). La lista básica de bienes primarios que propone Rawls, es aceptada por los individuos que participan de la cooperación social. Y es la siguiente:

a) derechos y libertades básicas, que también pueden presentarse en una lista;

b) libertad de movimientos y libre elección del empleo en un marco de oportunidades varias;

c) poderes y prerrogativas de cargos y posiciones de responsabilidad en las intuiciones políticas y económicas de la estructura básica;

d) ingresos y riqueza; y, por último,

e) las bases sociales del autorrespeto. (Rawls, 1993, p. 214)

En este sentido, la teoría propone los mismos bienes para todos los individuos, independiente de sus concepciones de vida buena, de forma igualitaria, como parte de un acuerdo moral para una sociedad justa. Podemos juzgar que estos bienes, en tanto cosas, corresponden a un enfoque de justicia en términos materiales.

La lista de bienes primarios que propone muestra que el modelo liberal considera su matriz igualitarista, en tanto los menos aventajados son dignos de reciprocidad y de autorrespeto. Con esto en mente, Rawls objeta al Estado de Bienestar capitalista el desarrollo de una subclase desmoralizada, deprimida y dependiente de las ayudas asistenciales. "Esta subclase se siente excluida y no participa de la cultura política pública” (Rawls, 2002, p. 190). Rawls critica al Estado de Bienestar por tratar a los destinatarios de los bienes como instrumentos de caridad, cuyas políticas serían una intromisión que impide que los in- 
dividuos construyan sus propias concepciones de vida buena, por eso la lista de bienes primarios parece amplia y poco vinculante en cuanto a garantías.

Llevando el presente marco normativo a un análisis práctico orientado a las instituciones, cabe señalar que los bienes que se entregaron por las medidas del gobierno de Sebastián Piñera, para atender la emergencia sanitaria por la covid-19, fueron insuficientes no solo porque su calidad era cuestionable, sino porque eran estandarizados, es decir, respondían a la universalización de la alimentación, que socava ciertos planes de vida que eligen otros alimentos, ya sea no cárnicos (siguiendo la etiqueta de carnes rojas o blancas) o de quienes no consumen lácteos. Siguiendo el enfoque normativo del "deber ser" de Rawls, es posible evaluar que las ayudas detonaron el incumplimiento de los principios de justicia, pues los individuos afectados por el hambre y la pérdida de trabajo no podían realizar y seguir con sus planes de vida buena, viéndose afectados, por la falta de ingresos, en su autonomía, en su autorrealización y en la vulneración de sus derechos. Lo que podemos considerar, siguiendo con este análisis normativo en contraste con la realidad, es que la ausencia de bienes primarios, como lo establece Rawls, es decir, la política (neo)liberal en el actual gobierno de Piñera a la luz de los supuestos rawlsianos, muestra el mal reparto de éstos, la universalización excluyente de otras formas de vida que no caben en el reparto estándar y acusa las injusticias producidas por la estructura básica?

\section{Algunas críticas a la justicia distributiva de Rawls}

Si bien existen diversas críticas a la teoría liberal de Rawls, cabe mencionar solo aquellas relacionadas con lo que hemos examinado.

Una de las críticas a la teoría liberal se refiere a la concepción individualista que está en el fondo de la ideología liberal, centrada en la defensa de las libertades individuales por sobre las colectivas, es decir,

7 En el escenario de confinamiento prolongado por la covid-19, la repartición de bienes se vislumbró de forma insuficiente, pues la gente debió dejar de trabajar y solo pudo acceder a su propio seguro de cesantía, que es propio de un modelo individualista neoliberal. En otros casos, a los bonos covid-19, a las cajas de alimentos y otras medidas que incumplieron los principios de justicia, en tanto no tomaron en cuenta las diferencias en las elecciones. 
el liberalismo de Rawls no admite reclamos de los grupos, ni reivindicaciones sociales, políticas y culturales, o reclamos identitarios, que son los que caracterizan los conflictos del último siglo.

Otra de las críticas apunta a la distribución de bienes estandarizados y hegemónicos respecto de las concepciones de vida buena. Esta es la posición de Iris Marion Young, filósofa estadounidense que cuestiona el modelo rawlsiano. Young plantea una crítica a la estructura básica del sistema institucional, pues, según dice, esta reproduce injusticias, al limitar el alcance de la justicia solo a lo distributivo y perder de vista las opresiones que se dan en el contexto institucional. En esta línea, la distribución cosifica a los individuos, es decir, la justicia designa una "noción de individuos separados ya formados con independencia de los bienes sociales" (Young, 2000, p. 66).

La crítica de la autora está dirigida a la concepción de la persona que está detrás de los bienes primarios, configurados como individuos receptores de bienes predeterminados para realizar sus planes de vida, lo cual manifiesta que están "ubicados en el terreno social como puntos a los que se asignan manojos más o menos grandes de bienes sociales" (Young, 2000, p. 36). Según Young, la concepción monológica de la justicia se traduce en que hay un solo modelo para todos los análisis de la justicia, es decir, todas las situaciones en las que la justicia está en cuestión son análogas a la situación de las personas que dividen una cantidad de bienes y comparan la medida de las porciones que los individuos tienen (Young, 2000, p. 36).

En esta línea, Brian Barry (1973) considera que los bienes primarios que admite Rawls responden a propósitos previamente calculados para mejorar condiciones de vida, a partir de un set de principios aplicados desde una situación hipotética. En efecto, la crítica de Barry expone que Rawls establece una lista de bienes estandarizados sobre las necesidades de los individuos y coarta la elección de bienes para satisfacer los distintos planes de vida.

Considerando lo anterior, la lógica de la justicia distributiva prescribe el carácter de los beneficiarios de los bienes y fomenta el egoísmo. Por consiguiente, solo fijarse en lo distributivo promueve el egoísmo de los individuos, puesto que la maximización del bien personal responde a una lógica instrumental en términos de costo-beneficios 
y atomizada respecto del modo de relacionarse. Es por eso que la crítica apela a ampliar la noción de justicia distributiva, y a considerar aspectos de las diferencias entre los individuos e incluir la categoría de "grupo" (Young, 2000) que el individualismo deja de lado.

La crítica de Young a la justicia distributiva denuncia que la concepción de la persona moral reproduce valores del liberalismo individualista y considera que las relaciones de los individuos con las instituciones producen injusticias que hay que revelar en términos políticos y democráticos por medio de la reivindicación de las diferencias. En este sentido, el aspecto normativo que caracteriza la teoría de Rawls es criticado, porque no contempla el dinamismo de los procesos sociales en los que conviven diferentes formas de vida, así como también se cuestiona que la normatividad de su enfoque niegue el conflicto y reproduzca las lógicas dominantes del statu quo.

\section{Aportes al Trabajo Social}

Respecto del Trabajo Social, los aportes del modelo rawlsiano permiten dar importancia a la responsabilidad de las instituciones a la hora de velar por una sociedad justa. Hemos de considerar como un aporte a la intervención social, conocer el marco teórico y normativo respecto de cómo está diseñada la estructura básica en sus referentes ideológicos, políticos y económicos. Por ello, los planteamientos de Rawls deben ser estudiados, para analizar y reflexionar hasta qué punto la teoría normativa del deber ser está lejos de la práctica y, por tanto, de las condiciones de posibilidad de intervenciones basadas en la justicia desde el Trabajo Social.

Dicho esto, es interesante contrastar el modelo de justicia predominante con las críticas que hace Young a la noción de justicia distributiva. Esto es fundamental para cambiar las prácticas institucionales y así evitar formas de opresión, lo que exige no considerar a los individuos como sujetos que, como víctimas, reciben bienes, sino como agentes de justicia. De este modo, el Trabajo Social tiene el doble desafío de cumplir con los principios de justicia que yacen en el seno de la institucionalidad, para desmarcarse de lo normativo y mediar las situaciones en las que el conflicto es latente, sobre todo cuando la estructura institucional tiende a reproducir formas de opresión hacia individuos que se ven presionados a asimilarse a la universalización de prestaciones y 
a aceptar el statu quo. Es preciso entonces considerar las particularidades y las distintas voces que reclaman reconocimiento, para así contribuir a no perpetuar injusticias.

En este sentido, el Trabajo Social emancipador está en concordancia con la justicia política que va más allá de la concepción distributiva, puesto que se dirige a fomentar el desarrollo de habilidades aptas para la participación de los individuos en una sociedad más justa, en la cual sea posible incidir en el futuro de las decisiones y en los bienes que se requieren para realizar los planes de vida buena. Esta perspectiva política de la justicia apunta al desarrollo de capacidades de autoorganización y de autorrealización, para lo cual el Trabajo Social debe apostar por el desarrollo de confianzas contra toda forma de opresión (Lizana, 2015).

Esto nos sitúa en el giro político de la justicia relacionado con el oír a las partes, con el reconocimiento y con procesos políticos potenciales de transformación social. Un terreno en que la distribución, entendida en los términos normativos stricto sensu, debe desplazarse de la justicia y, con ello, el Trabajo Social ha de alinearse con nociones que permitan potenciar la expresión de demandas, para que sean escuchadas y atendidas. Así, el giro político de la justicia remite a la capacidad de ampliar la noción de la justicia para escuchar a las partes como una posibilidad de hacer justicia.

Young y Agra apuestan por la justicia del oír. Ambas autoras citan en sus respectivas obras a Lyotard. Según dicho autor:

...un lenguaje es en primer lugar, y, ante todo, alguien hablando. Pero hay juegos del lenguaje en los que lo importante es escuchar, en los que las reglas tienen que ver con la audición. Tal juego es el juego de lo justo. Y en este juego uno habla solo en la medida en que escucha, es decir, uno habla como quien escucha, y no como un autor. (Lyotard, 1985 en Young, 2000, p.14 y en Agra, 2016, p.125)

El enfoque de la justicia de la escucha contiene una noción de la justicia que el Trabajo Social debe considerar en tiempos de crisis institucional, para abrir reflexiones y debates sobre la intervención social, con el propósito de minimizar las injusticias y repensar las formas en que se materializa la justicia social (Ruz, 2020). Sin embargo, contar con la concepción de la justicia política y de la escucha no implica 
abandonar la lógica distributiva, pues mientras existan desigualdades materiales, el quehacer profesional ha de gestionar las prestaciones que operan desde la estructura básica. La propuesta es combinar los enfoques de la justicia con los que el Trabajo Social debe saber lidiar, e identificar en qué medida interviene desde una noción distributiva de prestaciones que podrían generar injusticias, las que el contexto institucional pierde de vista. Para evitar esto, hemos de considerar otros enfoques que alienten procesos sociales en los que los individuos participen activamente, sean escuchados y atendidos en sus demandas.

\section{Conclusiones}

El enfoque distributivo de la justicia que expone John Rawls es el modelo predominante y, como tal, incide en el diseño de las instituciones públicas de base normativa, como el que hemos expuesto.

El carácter institucionalista es central en el enfoque rawlsiano, es decir, considera que las instituciones tienen la tarea de asegurar la justicia y que lo hacen por medio del respeto de ciertos principios que deben cumplir. Esto nos aproxima a entender cómo operan los marcos normativos y la distancia que tienen con la realidad, así como también la utilización de estos como un parámetro pertinente para valorar si las instituciones cumplen con los principios de libertad, según el encargo de la justicia distributiva imperante.

No obstante, las críticas expuestas nos recuerdan que el liberalismo de Rawls tiene un componente individualista que no toma en cuenta la vulnerabilidad que el cuadro histórico pone de relieve, puesto que ignora los procesos sociales. En este sentido, hemos de tener presente las ideas de Young sobre la importancia de reconocer las diferencias que existen entre las distintas formas de vida con las que la estructura básica se relaciona. Y, sobre todo, considerar la propuesta de la autora respecto de ampliar la justicia más allá de lo distributivo.

De acuerdo con los aportes al Trabajo Social, es relevante considerar que la disciplina, en tanto se inscribe en la estructura básica, debe estar vigilante al cumplimiento de los principios de justicia y esforzarse por entender las implicaciones de este modelo sobre la configuración instrumental con que se trata al individuo. En efecto, el sentido de examinar las concepciones de la teoría de Rawls apunta 
a identificar la lógica del enfoque de justicia bajo el cual se diseñan las políticas públicas desde la perspectiva dominante, que cosifica a los individuos y pierde de vista aspectos que no se pueden distribuir, ni cuantificar.

Con todo, las concepciones expuestas permiten preguntar: ¿hasta qué punto la justicia distributiva rige las intervenciones sociales, sobre todo cuando se trata de repartos, ya sea de prestaciones o de aspectos que tienen que ver con el poder, el autorrespeto, los derechos, entre otros bienes materiales o inmateriales que este enfoque intenta distribuir? Esta interrogante puede servir de brújula en el Trabajo Social al interior de la estructura básica, es decir, como una orientación práctica para avanzar hacia el horizonte ético, de manera de evitar que sean las instituciones las que, en la práctica, impidan a los individuos desarrollarse y cumplir con sus propósitos vitales, pues no solo se trata de cumplir con la entrega de beneficios, sino de contribuir a que las instituciones sean justas en sus procedimientos y en sus resultados.

\section{Bibliografía}

Agra, Ma. X. (1985). J. Rawls: El sentido de la justicia en una sociedad democrática. Santiago de Compostela: Universidad de Santiago de Compostela.

Agra, $\mathrm{M}^{\mathrm{a}}$. X. (2016). ¿Olvidar a Clitemnestra? Sobre justicia e igualdad. Santiago de Compostela: Universidad de Santiago de Compostela.

Barry, B. (1973). The Liberal Theory of Justice, A critical Examination of the Principal Doctrines in The Theory of Justice by John Rawls. Oxford: Oxford Clarendon Press.

Bermudo, J.M. (1975). El concepto de praxis en el joven Marx. Barcelona: Ediciones Península.

Garcés, M. (2020). Estallido social y una nueva constitución para Chile. Santiago: Lom Ediciones.

Gargarella, R. (1999). Las teorías de la justicia después de Rawls: un breve manual de filosofía política. Barcelona: Paidós.

Lassalle, J.M. (2010). Liberales: Compromiso cívico con la virtud. Barcelona: Debate.

Lizana, N. (2015). Justicia social y política en Iris Marion Young: Contribuyendo a un Trabajo Social Emancipador. Intervención 4. 
Repensar la intervención hoy, desafíos de la transformación social. Universidad Alberto Hurtado. Publicado 2015-0801 Recuperado de http://repositorio.uahurtado.cl/handle/11242/7370

Lorey, I. (2016). Estado de inseguridad. Gobernar la precariedad. Madrid: Traficantes de Sueños.

Macpherson, C.B. (2005) Una teoría del individualismo posesivo: de Hobbes a Locke. Madrid. Trotta.

Rawls, J. (1979). Teoría de la Justicia. México: Fondo de cultura Económica.

Rawls, J. (1993). Liberalismo Político. Barcelona: Crítica.

Rawls, J. (2002). La justicia como equidad: Una reformulación. Barcelona: Paidós.

Rolnik, S. (2019). Esferas de la insurrección: Apuntes para descolonizar e inconsciente. Buenos Aires: Tinta limón.

Ruz, C. (2020). ¿Qué justicia social queremos? Nociones para el trabajo social. Intervención 10 Núm 1. Reflexiones para tiempos de incertidumbre, pandemia y revuelta social. Universidad Alberto Hurtado. Publicado 2021-31-01 Recuperado de https:// intervencion.uahurtado.cl/index.php/intervencion/article/ view/93/125

Ruz, C. (2017). La virtud política en el liberalismo contemporáneo: de lo instrumental a lo dialéctico. (Tesis de doctorado). Barcelona: Universidad de Barcelona, Facultad de Filosofía.

Young, I. M. (2000). La justicia y la política de la diferencia. Madrid: Cátedra. 